DOI: 10.26699/jnk.v4i3.ART.p196-200

This is an Open Access article under the CC BY-SA license (http://creativecommons.org/licenses/by-sa/4.0/)

\title{
UPAYA ANTISIPASI PERILAKU SEX BEBAS DI KALANGAN MAHASISWI KEBIDANAN (STUDI PERANAN PENDIDIK DALAM MENGANTISIPASI SEX BEBAS DI KALANGAN MAHASISWI AKADEMI KEBIDANAN MEDIKA WIYATA KEDIRI) (The Study of the Role Of Educators in Anticipating Free Sex Behavior of Midwifery Students Of Medika Wiyata Kediri)
}

\author{
Is Fadhillah \\ Akademi Kebidanan Medika Wiyata Kediri \\ email: isfadhillah@gmail.com
}

\begin{abstract}
Deviation in adolescents occurred because of the promiscuity of free sex. One of the promiscu-ity that has a dominant influence on teenagers, especially college students in the campus is free sex. Sex as a natural human need in the effort fulfillment tend to be dominated by the instinct of sex instinct subjectively. As a result, there are frequent deviations and violations of sex behavior beyond the limits of honor and humanity's moral code. Though for midwifery students of the science they get they should better understand the consequences of sex freely outside of marriage, because of the science they learned is also taught many things about the disease resulting from free sex and the danger of pregnancy at an early age. The objective of this research was to know the role of Educator of Midwifery Academy of Akademi Kebidanan Medika Wiyata Kediri in doing social control and efforts in facing the deviation of student behavior in anticipating the occurrence of free sex, using qualitative approach. Data collection used interview and observation, then analyzed by descriptive qualitative. The social action theory that Talcot Parson finds to be a reference to discuss how social action can be formed in this study to obtain a common goal based on values and norms and rules that must be obeyed to form a student who has a good personality and moral.The role of educators in social control in anticipating free sex in female students of Akademi Kebidanan Medika Wiyata Kediri could be applied through social supervision, which was a system that educates, invites, and even forces female students to behave in accordance with the rules applicable in educational institutions that must obeyed and run by female students, with the aim of creating the order of female students in educational institutions. The social control of educators at the Akademi Kebidanan Medika Wiyata was conducted through preventive social control through prevention of the possibility of violations of the rules, or an attempt made prior to the occurrence of a violation and repressive social control through sanctions for female students who perform violation, in accordance with the rules applicable in Akademi Kebidanan Medika Wiyata Kediri.
\end{abstract}

Keywords: educator, social control, student, free sex

\begin{abstract}
Abstrak: Penyimpangan pada remaja banyak terjadi dipicu karena adanya pergaulan bebas. Salah satu pergaulan bebas yang mempunyai pengaruh dominan terhadap para remaja, terutama para mahasiswi di lingkungan kampus adalah sex bebas. Sex sebagai kebutuhan manusia yang alamiah tersebut dalam upaya pemenuhannya cenderung didominasi oleh dorongan naluri sex secara subyektif. Akibatnya sering terjadi penyimpangan dan pelanggaran perilaku sex di luar batas hak-hak kehormatan dan tata susila kemanusiaan. Mahasiswi kebidanan secara penguasaan ilmu seharusnya mereka lebih memahami akibat dari sex secara bebas di luar pernikahan, karena dari ilmu yang mereka pelajari juga diajarkan banyak hal tentang penyakit yang diakibatkan dari sex bebas dan juga bahaya kehamilan di usia dini. Penelitian ini bertujuan untuk mengetahui peranan Pendidik Akademi Kebidanan Medika Wiyata dalam melakukan kontrol sosial dan
\end{abstract}


upaya apa saja yang dilakukan dalam menghadapi penyimpangan perilaku mahasiswinya guna mengantisipasi terjadinya sex bebas, dengan menggunakan pendekatan kualitatif. Pengumpulan data dilakukan dengan wawancara dan observasi yang dikumpulkan, kemudian dianalisa secara diskriptif kualitatif. Kontrol sosial yang dilakukan para pendidik di Akademi Kebidanan Medika Wiyata dilakukan melalui pengendalian sosial preventiv melalui tindakan pencegahan terhadap kemungkinan terjadinya pelanggaran-pelanggaran terhadap peraturan, atau merupakan suatu usaha yang dilakukan sebelum terjadinya suatu pelanggaran dan pengendalian sosial secara represif melaui pemberian sanksi bagi mahasiswi yang melakukan pelanggaran, sesuai dengan peraturan yang berlaku di Akademi Kebidanan Medika Wiyata Kediri.

Kata kunci: Pendidik, Kontrol Sosial, Mahasiswi, Sex Bebas

Dewasa ini banyak terjadi penyimpangan sosial pada remaja, terutama pada mahasiswi di lingkungan kampus. Salah satu yang menyebabkan munculnya penyimpangan menurut pakar teori kontrol sosial cenderung beranggapan bahwa, ketika diberi pe-luang dan kesempatan, umat manusia pasti akan menyimpang (Ritzer,2013; 366). Penyimpangan yang banyak terjadi pada lingkungan mahasiswi diantaranya adalah pergaulan bebas. Pacaran meru-pakan salah satu bentuk pergaulan bebas yang men-jadi jalan utama munculnya penyimpangan seksual. Pacaran bagi mereka dianggap sebagai perbuatan yang tidak melanggar norma budaya masyarakat apalagi norma agama, karena dengan memiliki pasangan (pacar) itulah mereka berani memulai akti-vitas sexsual sampai ke titik puncaknya yaitu dengan melakukan sex bebas yang mengakibatkan terjadi-nya kehamilan di luar nikah.

Para remaja dalam hal ini mahasiswi lebih suka berbicara sex dikalangan teman-temannya. Jika hubungan intim itu terpisah atau mendapat hambatan, maka mereka tidak akan kehilangan jati diri dan lebih cepat untuk menyesuaikan diri dengan kehidupan dalam lingkungan pergaulan lainnya. Sebagai konsekuensi proses sosialisasi norma-norma yang berhubungan dengan batas-batas pola dan etika pergaulan semakin berkurang, maka pengaruh pola pergaulan bebas cenderung lebih dominan merasuk kedalam kebiasaan baru. Sex sebagai kebutuhan manusia yang alamiah tersebut dalam upaya pemenuhannya cenderung didominasi oleh dorongan naluri sex secara subyektif. Akibatnya sering terjadi penyimpangan dan pelanggaran perilaku sex di luar batas hak-hak kehormatan dan tata susila kemanusiaan. Padahal bagi mahasiswi kebidanan dari ilmu yang mereka dapatkan seharusnya mereka lebih memahami aki-bat dari sex secara bebas di luar pernikahan, karena dari ilmu yang mereka pelajari juga diajarkan banyak hal tentang penyakit yang diakibatkan dari sex bebas dan juga bahaya kehamilan di usia dini. Tapi ternyata hal tersebut tidak bisa dijadikan patokan untuk menanggulanginya. Sex bebas merupakan salah satu masalah pokok yang perlu di perhatikan,
Menurut BKKBN dalam Berita Nesstand, 2012 jumlah remaja di Indonesia terbilang besar yakni yaitu 26,7 persen dari total penduduk. Apabila tidak dipersiapkan dengan baik, maka remaja sangat beresiko terhadap perilaku sexsual pranikah..

Menurut hasil penelitian Kementrian Kesehatan di empat kota yakni Jakarta Pusat, Medan, Bandung dan Surabaya sebanyak 35,9 persen remaja memiliki teman yang sudah pernah melakukan hubungan sexsual sebelum menikah dan 6,9 persen responden telah melakukan hubungan sexsual pranikah (Merdeka.com, 2013). Beberapa hal yang mempengaruhi remaja dalam hal ini mahasiswi mahasiswi dalam melaku- kan perilaku sex bebas, diantaranya adalah gagalnya sosialisasi norma-norma dalam keluarga, terutama keyakinan agama dan moralitas; semakin terbuka- nya peluang pergaulan bebas; setara dengan kuanti- tas pengetahuan tentang perilaku sex pada lingkung- an sosial dan kelompok pertemanan; kekosongan aktivitas-aktivitas fisik dan rasio dalam kehidupan sehari-hari; sensitifitas penyerapan dan penghayatan terhadap struktur pergaulan dan sex bebas relatif tinggi; rendahnya keperdulian dan kontrol sosial; adanya kemudahan dalam mengantisipasi resiko kehamilan.

Berdasarkan alasan tersebut, maka semakin terbukalah pergaulan bebas antara pria dan wanita, terutama bagi kalangan mahasiswi di lingkungan kampus. Kebutuhan baru ini menuntut seseorang untuk membentuk sistem pergaulan modernitas yang cenderung meminimalisasi ikatan moral dan kepe-dulian terhadap hukum-hukum agama maupun pen-didikan. Bagi kalangan mahasiswi, sex merupakan indikasi kedewasaan yang normal, akan tetapi kare-na mereka tidak cukup mengetahui secara utuh ten-tang rahasia dan fungsi sex, maka lumrah kalau mereka menafsirkan sex semata-mata sebagai tem-pat pelampiasan birahi, dengan tidak memperdulikan resiko yang akan diperolehnya.

Popularitas perilaku sex bebas dalam kehidupan mahasiswi di lingkungan kampus juga didasari kare-na adanya tekanan dari lingkungan sekitar. Kemu- 
dian disusul oleh dorongan kebutuhan nafsu sex secara emosional, di samping karena rendahnya pemahaman tentang makna cinta dan rasa keingintahuan yang tinggi tentang sex. Ternyata dari beberapa mahasiswi mengungkapkan bahwa mereka melakukan sex di luar nikah karena tekanan sesama teman wanita yang yang menyalah artikan pergaulan bebas secara modern. Dengan adanya fenomena tersebut mempunyai pengaruh besar dari mahasiswi yang satu ke mahasiswi yang lain agar tidak disebut sebagai gadis kampungan, yang mengakibatkan mereka terperangkap dalam penyimpangan moral dengan mengalahkan kepribadian dan citra diri.

Hal lain yang menyebabkan mahasiswi melakukan sex bebas dikarenakan untuk membuktikan dan menunjukkan kekuatan cinta yang dimiliki terhadap pasangannya. Setelah sex tersebut ditemukan dalam praktek, maka terbentuklah perilaku yang namanya ketagihan. Di sinilah sex diartikan sebagai kepanjangan dari perasaan cinta. Dari latar belakang tersebut yang menjadikan Pendidik di Akademi Kebi-danan Medika Wiyata lebih meningkatkan kontrol sosial dan pengawasan pada mahasiswinya untuk mengantisipasi terjadinya sex bebas dikalangan mahasiswi yang semakin semarak di era modernisasi ini

Dari latar belakang yang sudah di uraikan, maka rumusan masalah yang dapat diangkat adalah bagaimana pendidik Akademi Kebidanan Medika Wiyata Kediri dalam melakukan kontrol sosial guna mengantisipasi penaggulangan sex bebas di kalangan mahasiswi dan upaya apa saja yang dilakukan Pendidik Akademi Kebidanan Medika Wiyata Kediri dalam mengantisipasi penyimpangan perilaku maha-siswinya dalam mengantisipasi terjadinya sex bebas.

Sedangkan tujuan penelitian ini adalah untuk mendiskripsikan Pendidik Akademi Kebidanan Medika Wiyata Kediri dalam melakukan kontrol sosial guna mengantisipasi penaggulangan sex bebas di kalangan mahasiswi serta untuk mengetahui upaya apa saja yang dilakukan Pendidik Akademi Kebidanan Medika Wiyata Kediri dalam mengantisipasi penyimpangan perilaku mahasiswinya guna mengantisipasi terjadinya sex bebas.

\section{BAHAN DAN METODE PENELITIAN}

Penelitian ini merupakan penelitian deskriptif kualitiatif. Populasi dalam penelitian ini adalah seluruh pengajar di Akademi Kebidanan Medika Wiyata. Sampel penelitian adalah 6 orang pendidik di Akademi Kebidanan Medika Wiyata Kediri dengan karakteristik usia minimal 30 tahun dan berpengalaman sebagai pendidik minimal 2 tahun. Teknik pengumpulan data menggunakan teknik wawancara.

\section{HASIL PENELITIAN}

Kontrol Sosial Pendidik dalam mengantisipasi pergaulan sex bebas pada mahasiswi Akademi Kebidanan Medika Wiyata Kediri dapat diartikan sebagai pengawasan sosial, yaitu suatu sistem yang mendidik, mengajak, dan bahkan memaksa mahasiswi agar berperilaku sesuai dengan aturan-aturan yang berlaku dalam lembaga pendidikan yang harus ditaati dan dijalankan oleh mahasiswi, dengan tujuan untuk menciptakan ketertiban mahasiswi dalam lembaga pendidikan. Upaya-upaya yang dilakukan para pendidik di Akademi Kebidanan dilakukan melalui pengendalian sosial preventif. Pengendalian sosial preventif adalah pengendalian yang bertujuan untuk melakukan tindakan pencegahan terhadap kemungkinan terjadinya pelanggaran-pelanggaran terhadap peraturan, atau merupakan suatu usaha yang dilakukan sebelum terjadinya suatu pelanggaran. Dalam pengendalian preventif mahasiswi diarahkan, diingatkan agar tidak melakukan pelanggaran yang telah disebutkan. Terkait kontrol sosial yang dilaku-kan pendidik diantaranya; menyisipkan pesan mora-litas pada mahasiswi setiap melakukan pengajaran pada jam perkuliahan; mengikutsertakan mahasiswi dalam kegiatan Tri Darma Perguruan Tinggi; me-ningkatkan kegiatan kemahasiswaan di luar jam perkuliahan; mengadakan kegiatan PP Test pada mahasiswi di luar jadwal kegiatan perkuliahan, yang dilakukan secara mendadak; melakukan pendam-pingan secara continue pada mahasiswi yang mem-punyai masalah. Selain pengendalian sosial pre-ventif, kontrol sosial pendidik yang lainnya antara lain adalah pengendalian sosial represif

Pengendalian sosial represif adalah bentuk pengendalian sosial yang dilakukan setelah terjadinya suatu pelanggaran atau merupakan bentuk pengendalian dimana penyimpangan sosial sudah terjadi kemudian dikembalikan lagi agar situasi sosial menjadi normal. Berdasarkan hasil penelitian, sete-lah melakukan pengendalian sosial preventif, para pendidik kemudian melakukan pengendalian yang bersifat represif dimana pendidik berusaha mengembalikan keserasian yang sempat terganggu, yaitu dengan memberikan sanksi bagi mahasiswi yang melakukan pelanggaran akibat dari pergaulan bebas, 
sesuai dengan peraturan yang berlaku di Akademi Kebidanan Medika Wiyata Kediri. Dari hasil penelitian diperoleh salah satu bentuk sanksi yang diberikan pada mahasiswi yang melakukan pelanggaran hamil di luar nikah akan dikeluarkan dari institusi

\section{PEMBAHASAN}

Dalam mempelajari dan mengembangkan keilmuan terutama ilmu sosial, digunakan berbagai teori untuk menerangkan berbagai fenomena sosial yang terjadi di sekeliling kita. Dalam khznah pengetahuan tentang kontrol sosial pendidik terhadap mahasiswi khususnya di kebidanan dalam megantisipasi pergaulan sex bebas terdapat banyak teori yang berkembang dan dijadikan rujukan dalam menganalisis permasalahan di dalamnya, teori yang dimaksud adalah Teori Tindakan Atau Aksi Parsons.

Teori bertindak atau aksi Parsons dipengaruhi oleh Durkheim, Marshall dan Pareto maupun Weber yang menekankan faktor-faktor situasional yang membantu tindakan individu. Dalam teori kaum Parsonian, konsep "tindakan rasional" Weber dilanjut-kan sebagai ide inti. Parsons melihat sistem sosial sebagai satu dari tiga cara dimana tindakan sosial bisa terorganisir. Disamping itu terdapat dua sistem tindakan lain yang saling melengkapi, yaitu; sistem kultural yang mengandung nilai dan simbol-simbol serta sistem kepribadian para pelaku individual. (Poloma, 2010;170-171). Talcott Parsons merupa-kan pengikut Weber utama. Teori Aksi yang dikembangkan mendapat sambutan luas. Parsons seperti pengikut Trori Aksi lainnnya menginginkan pemisah anta Teori Aksi dengan aliran behaviorisme. Dipilihnya istilah "action" bukan "behavior" karena menurutnya mempunyai konotasi yang berbeda. "Bebavior" secara tidak langsung menyatakan kesesuaian secara mekanik antara perilaku "respon" dengan rangsangan dari luar (stimulus). Sedangkan istilah "action" menyataan secara tidak langsung suatu aktivitas, kreativitas dan proses penghayatan diri individu. (Ritzer, 2011;48)

Kesimpulan utama yang dapat di ambil adalah bahwa tindakan sosial merupakan suatu proses dimana aktor terlibat dalam pengambilan keputusan-keputusan subyektif tentang sarana dan cara untuk mencapai tujuan tertentu yang telah dipilih, yang kesemuanya itu dibatasi dengan kemugkinan-ke-mungkinannya oleh sistem kebudayaan dalam ben-tuk norma-norma, ideide dan nilai-nilai sosial.Di dalam menghadapi situasi yang bersifat kendala baginya itu, aktor mempunyai sesuatu di dalam dirinya berupa kemauan bebas.(Ritzer, 2011; 49-50).

Dalam penelitian ini, teori tindakan sosial menu-rut Parsons dapat digunakan sebagai dasar landasan peran pendidik dalam melakukan kontrol sosial terhadap peserta didiknya khususnya di Akademi Kebidanan Medika Wiyata Kediri. Upaya pendidik dalam mengantisipasi pergaulan sex bebas tidak dapat dipandang sebelah mata. Hal ini dikarenakan apa yang dilakukannya mempunyai banyak tujuan dan manfaat yang positif terutama dalam mem-bentuk kepribadian moral yang positif bagi mahasis-winya.

Paradigma yang digunakan adalah definisi sosial. Weber sebagai pengemuka exemplar dari paradigma ini mengartikan sosiologi sebagai studi tentang tindakan sosial antar hubungan sosial. Dima-na yang dimaksudkan dengan tindakan sosial disini adalah tindakan individu sepanjang tindakannya itu mempunyai makna atau arti subyektif bagi dirinya dan diarahkan kepada tindakan orang lain. (Ritzer, 2011:38)

Bertolak dari konsep dasar tentang tindakan sosial dan antar hubungan social Weber mengemukakan 5 ciri pokok yang menjadi sasaran penelitian sosiologi yaitu: tindakan manusia, yang menurut si aktor mengandung makna yang subyektif. Ini meliputi berbagai tindakan nyata; tindakan nyata dan yang bersifat membatin sepenuhnya dan bersifat subyektif; indakan yang meliputi pengaruh positif dari suatu situasi, tindakan yang sengaja diulang serta tindakan dalam bentuk persetujuan secara diam-diam; tindakan itu diarahkan kepada seseorang atau kepada beberapa individu; tindakan itu memperha-tikan tindakan orang lain dan terarah kepada orang lain itu.

Selain daripada ciri-ciri tersebut diatas, tindakan sosial masih mempunyai ciri-ciri lain. Tindakan sosial dapat pula dibedakan dari sudut waktu, sehingga ada tindakan yang diarahkan kepada waktu sekarang, waktu lalu atau waktu yang akan datang. Dilihat dari segi sasarannya, maka "pihak sana" yang menjadi sasaran tindakan sosial si aktor dapat berupa seseorang individu atau sekumpulan orang (Ritzer, 2011:39).

Dalam penelitian ini pendidik mampu melakukan tindakan sosial dalam mangantisipasi pergaulan bebas di Akademi Kebidanan Medika Wiyata Kediri. Hal ini membuktikan bahwa adanya peranan pen-didik dalam melakukan kontrol sosial terhadap ma- 
hasiswinya merupakan salah satu faktor terpenting dalam upaya menciptakan ketertiban dan kebaikan bersama untuk saat ini maupun masa yang akan datang sesuai tujuan bersama dalam membentuk mahasiswi kebidanan yang berbudi luhur.

Dari teori tindakan sosial Parson yang telah di jelaskan dapat kami analisis dari hasil penelitian bahwa ketika telah disepakati sebagai seorang peserta didik (mahasiswi) dengan berbagai hal yang terkait seperti mengenai hak dan kewajiban maha-siswi sebagai kaum terdidik khususnya di Akademi Kebidanan Medika Wiyata Kediri ialah merasa bersatu antara mahasiswi dengan lembaga pendidik-an, saling berhubungan dan saling menjaga peraturan yang berlaku. Hendaknya dari sudut pandang teori ini mampu mencapai tujuan yakni menciptakan ketertiban bersama. Melihat kasus penyimpangan pergaulan sex bebas yang kerap terjadi dapat saya analisis melalui struktur dan tindakan. Berdasarkan teori ini hendaknya terjadi kesadaran mahasiswi di lingkungan kampus, karena berdasarkan nilai dan norma serta aturan yang ditetapkan harus dipatuhi untuk mencapai tujuan bersama. Sex bebas sebagai tindakan pada suatu kondisi yang mungkin unsur-unsur yang terdapat diantaranya seperti, tujuan, situasi, dan norma ada yang tidak benar (salah). Dalam kejadiannya individu mahasiswi tidak hanya dipengaruhi oleh unsur tersebut namun juga oleh orientasi subjektifnya masingmasing.

Terjadinya perilaku sex bebas merupakan sebuah tindakan menyimpang karena individu maupun kelompok lupa atau tidak menyadari terhadap fungsi yang telah disepakatinya sebagai pelajar (maha-siswi) dalam mengindahkan nilai, ide dan norma yang disepakati. Hal ini dapat dipengaruhi oleh unsur tindakan yang menyeleweng atau dari diri (orientasi subjektifnya) sendiri.

Hal inilah yang menjadikan para pendidik Akademi Kebidanan Medika Wiyata lebih meningkatkan kontrol sosial bagi mahasiswinya melalui beberapa cara, untuk mencapai ketertiban dari peraturan yang telah disepakati bersama. Kontrol sosial pendidik sebagai tindakan pada suatu kondisi yang unsur-unsur di dalamnya meliputi, alat, tujuan, situasi, dan norma yang digunakan untuk mengantisipasi penyimpangan pergaulan sex bebas pada mahasiswi Akademi Kebidanan Medika Wiyata Kediri.

\section{SIMPULAN DAN SARAN}

\section{Simpulan}

Setelah dianalisis serta diinterpretasikan dalam pembahasan, maka dapat disimpulkan sesuai dengan rumusan masalah bahwa kontrol sosial pendidik dalam mengantisipasi pergaulan sex bebas dikalang-an mahasiswi Akademi Kebidanan Medika Wiyata Kediri yang terkait dalam teori ini adalah terjadinya pergaulan sex bebas merupakan sebuah tindakan menyimpang karena individu maupun kelompok lupa atau tidak menyadari terhadap fungsi yang telah disepakatinya sebagai mahasiswi dengan mengindahkan nilai, ide dan norma yang disepakati. Hal ini dapat dipengaruhi oleh unsur tindakan yang menyeleweng atau dari diri (orientasi subjektifnya) sendiri. Hal inilah yang menjadikan para pendidik lebih meningkatkan kontrol sosial bagi mahasiswinya. Kontrol sosial yang dilakukan diantaranya melalui kontrol sosial yang bersifat preventif dan represif.

\section{Saran}

Adapun solusi yang dapat diberikan antara lain: Senantiasa menanamkan pesan moral pada maha-siswi di setiap kesempatan, menanamkan selalu nilai-nilai positif, kesadaran akan norma dan peraturan yang berlaku baik di masyarakat maupun lingkungan pendidikan, menumbuhkembangkan nilai-nilai ke-agamaan terhadap peserta didik sejak usia dini hingga masyarakat tua.

\section{DAFTAR RUJUKAN}

BKKBN : Seks Bebas Masalah Utama Remaja. 28 Nopember 2012. Berita Satu Newstand Jakarta.

Kemenkes: 35,9 Persen Remaja Indonesia Lakukan Seks Bebas 01 April 2013. Merdeka.com. Jakarta

Poloma, Margaret M.2010. Sosiologi Kontemporer. PT. Raja Grafindo Persada, Jakarta.

Ritzer george. 2011. Sosiologi Ilmu Pengetahuan Berparadigma Ganda. PT. Raja Grafindo Jakarta.

Ritzer, Goerge. 2013. The Wiley Blackwell Companion To Sociology. Pustaka Pelajar, Yogyakarta. 